\title{
Nanoparticulate Dye-Semiconductor Hybrid Materials Formed by Electrochemical Self-Assembly as Electrodes in Photoelectrochemical Cells
}

Kazuteru Nonomura ${ }^{\mathrm{a}}$, Thomas Loewenstein ${ }^{\mathrm{a}}$, Esther Michaelis ${ }^{\mathrm{b}}$, Peter Kunze ${ }^{\mathrm{d}}$, Manuela Schiek ${ }^{\mathrm{d}}$, Jens Reemts ${ }^{\mathrm{c}}$, Mirian Yoshie Iwaya ${ }^{\mathrm{e}}$, Michael Wark $^{\mathrm{f}}$, Jiri Rathousky ${ }^{\mathrm{g}}$, Katharina Al-Shamery ${ }^{\mathrm{d}}$, Achim Kittel ${ }^{\mathrm{c}}$, Jürgen Parisi ${ }^{\mathrm{c}}$, Dieter Wöhrle $^{\mathrm{b}}$, Tsukasa Yoshida ${ }^{\mathrm{e}}$, and Derck Schlettwein ${ }^{\mathrm{a}}$

${ }^{a}$ Institut für Angewandte Physik, Justus-Liebig-Universität Gießen, Heinrich-Buff-Ring 16, 35392 Gießen, Germany

a Institut für Organische und Makromolekulare Chemie, Universität Bremen, Germany

${ }^{c}$ Abteilung Energie- und Halbleiterforschung, Institut für Physik, Universität Oldenburg, Germany

d Physikalische Chemie 1, Institut für Reine und Angewandte Chemie, Universität Oldenburg, Germany

e Environmental and Renewable Energy Systems, Faculty of Engineering, Gifu University, Japan

${ }^{\mathrm{f}}$ Institut für Physikalische Chemie und Elektrochemie, Universität Hannover, Germany

$\mathrm{g}$ J. Heyrovsky Institute of Physical Chemistry, Academy of Sciences of the Czech Republic, Prague, Czech Republic

Reprint requests to J. P.; E-mail: parisi@ehf.uni-oldenburg.de

Z. Naturforsch. 64a, 518 -530 (2009); received January 26, 2009

\begin{abstract}
Dye-sensitized zinc oxide thin films were prepared, characterized and optimized for applications as photoelectrochemically active electrodes. Conditions were established under which crystalline thin films of $\mathrm{ZnO}$ with a porous texture were formed by electrochemically induced crystallization controlled by structure-directing agents (SDA). Dye molecules were adsorbed either directly as SDA during this preparation step or, preferably, following desorption of a SDA. The external quantum efficiency (IPCE) could thereby be increased significantly. Particular emphasis was laid on dye molecules that absorb in the red part of the visible spectrum. Model experiments under ultrahigh vacuum (UHV) conditions with dye molecules adsorbed on defined crystal planes of single crystals aimed at a deeper understanding of the coupling of the chromophore electronic $\pi$-system within molecular aggregates and to the semiconductor surface. Detailed photoelectrochemical kinetic measurements were used to characterize and optimize the electrochemically prepared dye-sensitized $\mathrm{ZnO}$ films. Parallel electrical characterization in vacuum served to distinguish between contributions of charge transport within the $\mathrm{ZnO}$ semiconductor matrix and the ions of the electrolyte in the pore system of the electrode.
\end{abstract}

Key words: Electrodeposition; Photosensitization; Film Growth; Adsorption; Electrical Conduction.

\section{Introduction}

Dye-sensitized electrodes of wide-bandgap semiconductors like $\mathrm{TiO}_{2}$ or $\mathrm{ZnO}$ represent a photochemical approach to a regenerative solar cell that provides both considerable fundamental insight and technical promise [1-4]. Even if $\mathrm{TiO}_{2}$ is the most successful electrode material up to now [4] $\mathrm{ZnO}$ offers important advantages for technical applications [5-12] mainly since crystalline films can be obtained by electrochemical deposition during electrolysis of aqueous zinc salt solutions without any annealing steps that would limit the choice of substrates. Earlier, we re- ported the successful preparation of dye-loaded $\mathrm{ZnO}$ semiconductor thin films by electrodeposition in the presence of water-soluble dyes based on simultaneous self-assembly of $\mathrm{ZnO}$ and the adsorbed dye, yielding a homogeneously coloured $\mathrm{ZnO}$ film with porous morphology [13]. Recently we have shown that improved overall conversion efficiencies $\leq 2.3 \%$ of photoelectrochemical cells consisting of $\mathrm{ZnO} /$ dye hybrid thin films can be achieved by extension of the onestep procedure towards a two-step procedure that consists of dye-desorption after electrodeposition and subsequent adsorption of a wide choice of sensitizer molecules [14]. 
Table 1. Sample porosity calculated from film thickness and Zn-content of the films and specific surface area from Krypton adsorption of a $1.5 \mu \mathrm{m}$ thick film grown in the presence of Eosin Y, following Eosin Y extraction, and following adsorption of either Eosin Y, TSPcZn or N3 for $1 \mathrm{~h}$ in the respective dye solution.

\begin{tabular}{ccccc}
\hline Porosity & \multicolumn{3}{c}{$\begin{array}{c}\text { Specific surface area (surface area in } \mathrm{cm}^{2} \text { divided by the geometric film area in } \mathrm{cm}^{2} \text { ) } \\
\text { following adsorption of } \\
\text { following extraction of the SDA }\end{array}$} & $\begin{array}{c}\text { Eosin Y } \\
\text { NSPcZn }\end{array}$ \\
\hline $63 \%$ & $\sim 1$ & $110(220)^{*}$ & 127 & 66 \\
\hline
\end{tabular}

* Value determined for a film of $3 \mu \mathrm{m}$ average film thickness.

In the present contribution we will show how this approach can be utilized to tune in detail the $\mathrm{ZnO}$ electrode structure and morphology by extending the range of both structure-directing agents (SDA) and sensitizer molecules. The photoelectrochemical characteristics of the obtained materials will be analyzed and model experiments will be used to reveal the role of surface interactions and charge conduction in the matrix materials.

\section{Results and Discussion}

\subsection{Role of Dye Agglomeration and Pore Accessibility for the Performance of Electrodes}

The two-step preparation method was used to increase the efficiency of cis-bis(isothiocyanato)-bis (2,2'-bipyridyl-4,4'-dicarboxylato)-ruthenium(II) (N3) as a sensitizer for $\mathrm{ZnO}$. N3 had proven almost ideal for the sensitization of $\mathrm{TiO}_{2}$ with a high external quantum efficiency (incident photon conversion efficiency IPCE) above $80 \%$ over a wide range of the visible spectrum [4]. For films of $\mathrm{ZnO}$ deposited in the presence of N3, however, quite poor performance at IPCE $<5 \%$ was observed [15]. The efficiency increased to IPCE $<50 \%$ in the two-step preparation when the disodium salt of 2-(2,4,5,7-tetrabromo-6-hydroxy-3-oxo$3 \mathrm{H}$-xanthene-9-yl) benzoic acid (Eosin Y) was used as SDA, removed in aqueous $\mathrm{KNO}_{3}$ and finally $\mathrm{N} 3$ was allowed to adsorb from a solution in ethanol (Fig. 1). An improved efficiency for N3 could be reached if N3 was adsorbed in the $\mathrm{ZnO}$ pores and the pores were still accessible to the electrolyte and agglomerate formation of $\mathrm{N} 3$ at the electrode surface as also proven by time-resolved photocurrent measurements [16].

Since the accessibility of pores in $\mathrm{ZnO}$ is a fundamental prerequisite to obtain sensitized electrodes of high efficiency, gas sorption experiments were performed on the thin films to directly measure the accessible sample surface area (related to $1 \mathrm{~cm}^{2}$ of the support) and compared to the overall pore volume (given as porosity) estimated from the deposited amount of

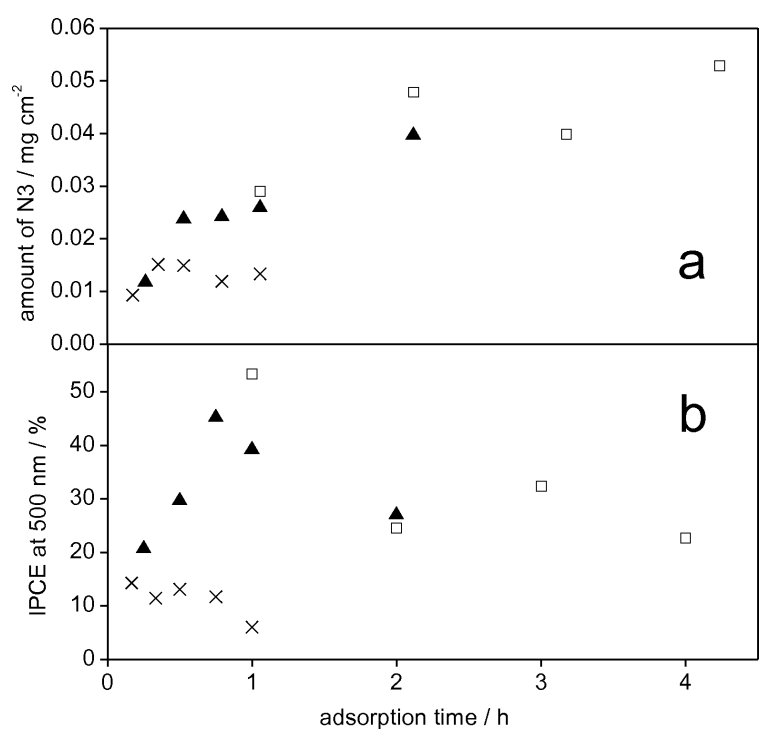

Fig. 1. (a) Amount of $\mathrm{N} 3$ taken up by films of $\mathrm{ZnO}$ (twostep procedure with Eosin $\mathrm{Y}$ as SDA) with an average film thickness of $0.6 \mu \mathrm{m}(\times, 68 \%$ porosity $), 2.4 \mu \mathrm{m}(\boldsymbol{\Lambda}, 64 \%$ porosity), and $2.5 \mu \mathrm{m}$ ( $\square, 55 \%$ porosity) during adsorption of $\mathrm{N} 3$ from a solution in ethanol and (b) external quantum efficiency (IPCE) of the films at the wavelength of $500 \mathrm{~nm}$ and a photon flux of $5 \cdot 10^{15}$ photons $\mathrm{s}^{-1} \mathrm{~cm}^{-2}$.

$\mathrm{ZnO}$, the average film thickness, and the density of $\mathrm{ZnO}$. Krypton had to be used as adsorptive gas because the very small absolute surface area of the samples in the range of only tens or hundreds square centimeters require a significantly improved accuracy of the measurements [17]. The results are summarized in Table 1 for Eosin $\mathrm{Y}$ as SDA and three different sensitizers: N3, Eosin Y, and 2,9,16,23-tetrasulfophthalocyaninatozinc (TSPcZn). In spite of $63 \%$ porosity calculated from the composition and thickness of the film, a negligible Krypton uptake was found for the as-deposited film (specific surface area of only a few $\mathrm{cm}^{2} / \mathrm{cm}^{2}$ designated as 1 in Table 1). The surface area was considerably increased after Eosin Y desorption and then decreased again upon adsorption of N3. In the case of Eosin Y or TSPcZn the specific surface area stayed considerably higher or even increased. Therefore, the 
(a)

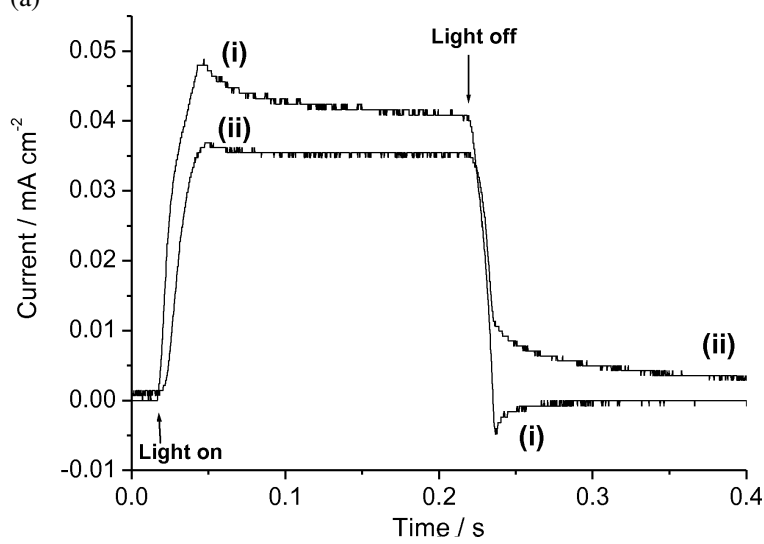

(b)

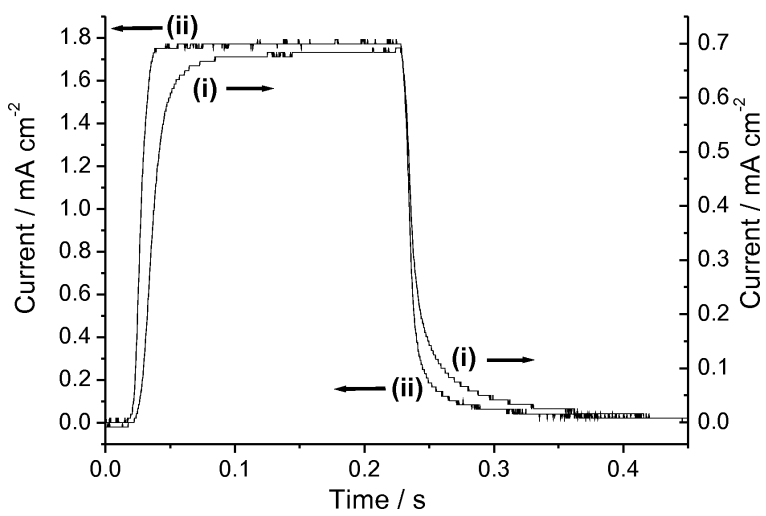

Fig. 2. Transient photocurrent measured at (a) one-step films of TSTPPZn/ZnO (i), TSPcZn/ZnO (ii) and (b) two-step films of TSTPPZn/ZnO (i), TSPcZn/ZnO (ii) under illumination with visible light (385-900 nm, light intensity: $200 \mathrm{~mW} \mathrm{~cm}$ ) in contact with acetonitrile-ethylene carbonate $(\mathrm{v} / \mathrm{v}=4: 1)$ containing $0.5 \mathrm{M}$ TBAI and $0.05 \mathrm{M} \mathrm{I}_{2}$ at an electrode potential of $-0.2 \mathrm{~V}$ vs. $\mathrm{Ag} / \mathrm{NO}_{3}$.

adsorption conditions especially for N3 if used as a sensitizer have to be adjusted very carefully to leave the pores accessible (Fig. 1, Table 1) and to avoid pore blocking.

It is one of the main goals to find alternative sensitizers, that are readily available, that absorb in the long wavelength part of the visible spectrum, and that do not interact in such a destructive way with the $\mathrm{ZnO}$ films as the N3 Ru complex. A large part of the photoelectrochemical study was therefore dedicated to the detailed study of TSPcZn as sensitizer. Because of their close structural relation and to provide an example of independently absorbing sensitizers in one film (pan-chromatic sensitization) 5,10,15,20-tetrakis (4-sulfonatophenyl)porphyrinatozinc (TSTPPZn) was also studied. Hybrid thin films of crystalline $\mathrm{ZnO}$ modified by TSPcZn and/or TSTPPZn were prepared by electrochemical deposition from aqueous zinc salt solutions in either the "one-step" process with the sensitizers adsorbed during $\mathrm{ZnO}$ deposition or by the "two-step" method by chemical adsorption of the sensitizers to $\mathrm{ZnO}$ that had been grown independently in the presence of Eosin Y as SDA. In films containing both sensitizers, they worked in parallel providing pan-chromatic sensitization. Recombination of electrons injected into the conduction band of $\mathrm{ZnO}$ with remaining defect electrons (holes) in the highest occupied molecular orbital (HOMO) of the sensitizers was indicated for the one-step films by the overshoot of the photocurrent (Fig. 2a), but was considerably suppressed for the films prepared by the two- step method (Fig. 2b) showing an almost rectangular response, standing for widely suppressed recombination. At a closer view, a rather slow increase of the photocurrent was observed upon opening of the shutter and the photocurrent decayed quite slowly after closure of the shutter. This observation indicates reversible trapping and detrapping of charge, most likely in electron traps of the $\mathrm{ZnO}$ semiconductor. Since TSPcZn/ZnO with its higher photocurrent obviously was able to fill these traps faster, an almost ideal rectangular response was observed.

The increased surface area and suppressed recombination led to a significantly increased photocurrent for the films prepared by the two-step method (Fig. 2). This could also be seen in a maximum IPCE $=10 \%$ (TSTPP) and IPCE $=12 \%($ TSPcZn) for the twostep films as opposed to IPCE $=0.14 \%$ (TSTPP) and IPCE $=0.6 \%$ (TSPcZn) for the one-step films [18]. It is interesting to note that in these cases the $\mathrm{ZnO}$ film thickness and even the dye load or dye concentration could be quite similar (Table 2) and still gave significantly better performance for the films prepared by the two-step method, also seen in a clearly increased photocurrent when normalized to the amount of sensitizers in the films (Table 2). The highest value was reached for $\mathrm{TSPcZn} / \mathrm{ZnO}$ prepared by the twostep method, speaking for the highest quantum efficiency in this case. Also for the films with both sensitizers present the two-step preparation gives considerably more efficient electrodes than the preparation in one step. 
Table 2. Dye content and average film thickness of the investigated films and comparison of the observed photocurrents $i_{\mathrm{ph}}$ at an incident photon flux of $10^{16} \mathrm{~s}^{-1} \mathrm{~cm}^{-2}$ normalized for the given dye content to provide a rough measure of the sensitization efficiency.

\begin{tabular}{|c|c|c|c|c|c|c|}
\hline Electrode material & $\begin{array}{c}\text { dye content/ } \\
10^{-9} \mathrm{~mol} \mathrm{~cm}^{-2}\end{array}$ & $\begin{array}{c}\text { film thickness/ } \\
\mu \mathrm{m}\end{array}$ & $\begin{array}{c}\text { dye content/ } \\
10^{-5} \mathrm{~mol} \mathrm{~cm}^{-3}\end{array}$ & $\begin{array}{c}\text { normalized } \\
i_{\mathrm{ph}}(430 \mathrm{~nm}) / \mathrm{s}^{-1}\end{array}$ & $\begin{array}{c}\text { normalized } \\
i_{\mathrm{ph}}(560 \mathrm{~nm}) / \mathrm{s}^{-1}\end{array}$ & $\begin{array}{c}\text { normalized } \\
i_{\mathrm{ph}}(680 \mathrm{~nm}) / \mathrm{s}^{-1}\end{array}$ \\
\hline \multicolumn{7}{|l|}{ one-step } \\
\hline $\mathrm{TSPcZn} / \mathrm{ZnO}$ & 11.7 & 2.6 & 4.5 & & & 0.08 \\
\hline \multicolumn{7}{|l|}{ one-step } \\
\hline TSTPPZn/ZnO & 16.2 & 2.7 & 6.0 & 0.14 & 0.06 & \\
\hline \multicolumn{7}{|l|}{ one-step ${ }^{\mathrm{a}}$} \\
\hline \multirow{3}{*}{$(\mathrm{TSPcZn}+\mathrm{TSTPPZn}) / \mathrm{ZnO}$} & 0.642 & & & & & \\
\hline & $\begin{array}{c}\text { TSPcZn } \\
13\end{array}$ & 2.2 & 0.29 & 0.10 & 0.05 & 0.52 \\
\hline & TSTPPZn & & 6.0 & & & \\
\hline one-step ${ }^{\mathrm{b}}$ & 1.37 & & & & & \\
\hline \multirow[t]{2}{*}{$(\mathrm{TSPcZn}+\mathrm{TSTPPZn}) / \mathrm{ZnO}$} & $\begin{array}{c}\text { TSPcZn } \\
29.1\end{array}$ & 5.2 & 0.26 & 0.03 & 0.03 & 0.72 \\
\hline & TSTPPZn & & 5.6 & & & \\
\hline \multicolumn{7}{|l|}{ two-step } \\
\hline $\mathrm{TSPcZn} / \mathrm{ZnO}$ & 2.38 & 3.0 & 0.79 & & & 87.44 \\
\hline \multicolumn{7}{|l|}{ two-step } \\
\hline TSTPPZn/ZnO & 17.4 & 2.5 & 6.9 & 14.54 & 3.73 & \\
\hline two-step & 4.30 & & & & & \\
\hline \multirow[t]{2}{*}{$(\mathrm{TSPcZn}+\mathrm{TSTPPZn}) / \mathrm{ZnO}$} & $\begin{array}{c}\text { TSPcZn } \\
5.43\end{array}$ & 3.0 & 1.4 & 32.91 & 6.86 & 37.59 \\
\hline & TSTPPZn & & 1.8 & & & \\
\hline
\end{tabular}

a Prepared in the presence of $25 \mu \mathrm{M}$ of TSPcZn and $25 \mu \mathrm{M}$ of TSTPPZn in the preparation solution.

${ }^{\mathrm{b}}$ Prepared in the presence of $50 \mu \mathrm{M}$ of TSPcZn and $50 \mu \mathrm{M}$ of TSTPPZn in the preparation solution.

\subsection{Optimized Structure-Directing Agents and Their Role in the Electrodeposition of Porous $\mathrm{ZnO}$}

To increase the porosity and surface area beyond the level reached with Eosin Y, different types of SDA were studied in the deposition of highly porous $\mathrm{ZnO}$ films from oxygen saturated $\mathrm{ZnCl}_{2}$ solutions. Films were deposited in the presence of different small molecules like benzoic acid, p-toluene sulfonic acid, and benzene tetracarboxylic acid as model compounds and of sodium dodecyl sulfate (SDS) as a representative of an anionic surfactant [19]. A mixed aqueous solution of $\mathrm{ZnCl}_{2}$ and $\mathrm{KCl}$ served as a bath for the electrodeposition of the $\mathrm{ZnO}$ films. The different SDA were added in increments to the deposition mixture from concentrated stock solutions in $50 \mu \mathrm{M}$ (calculated concentration in the deposition bath) steps, which allowed to follow the rate of the film growth and especially the effect of additives on it in detail by measuring the time evolution of the observed current density of $\mathrm{ZnO}$ deposition. Whereas the current density usually reached only $0.15 \mathrm{~mA} / \mathrm{cm}^{2}$ in the deposition of pure $\mathrm{ZnO}$ [20], the current increased to more than

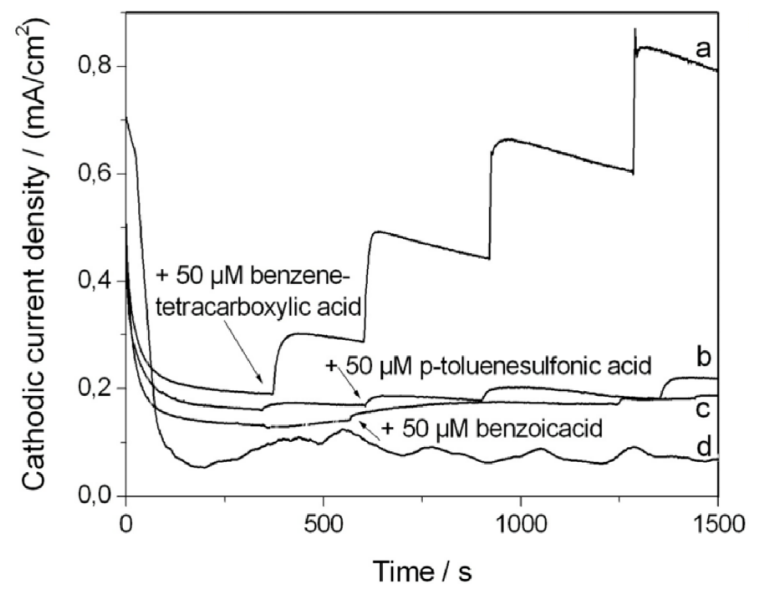

Fig. 3. Time evolution of the cathodic current density of $\mathrm{ZnO}$ electrodeposition during the step-wise addition of benzene tetracarboxylic acid (a), p-toluenesulfonic acid (b), benzoic acid (c) and without any addition (d).

$1 \mathrm{~mA} / \mathrm{cm}^{2}$ in the presence of $50 \mu \mathrm{mol}$ of some negatively charged dyes, e. g. Eosin Y, because of the catalytic effect of the dyes on the electrodeposition [21]. If benzoic acid was added, the resulting current increased 


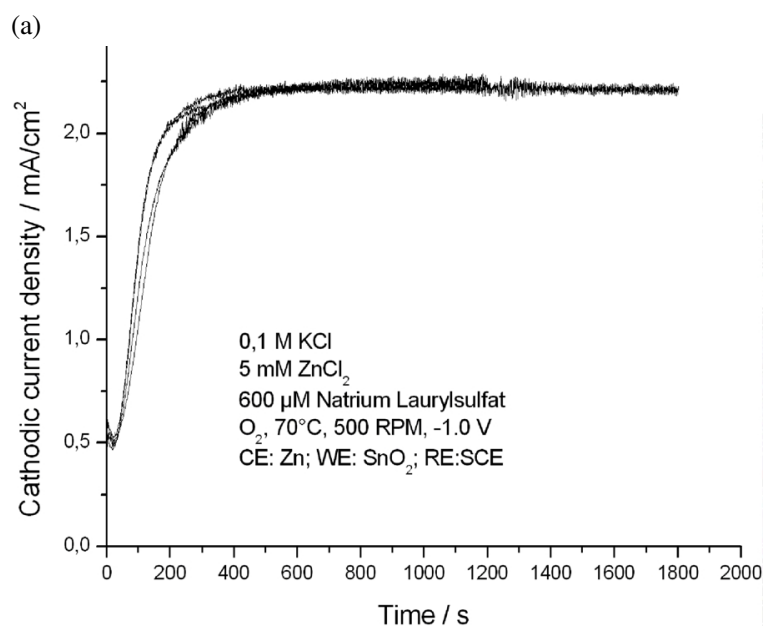

only slightly (Fig. 3). During the addition of p-toluene sulfonic acid, however, a marked increase in the cathodic current density became apparent. With benzene tetracarboxylic acid, the effect is even larger, and big steps in the current density were observed for each addition of the SDA (Fig. 3). The increase in the current density during deposition seems to be correlated mainly with the number of acid groups in the SDA molecules and strong differences were observed. However, when the morphology of the deposited ZnO/SDA films obtained at the same concentration of $50 \mu \mathrm{M}$ of each acid was compared, only small differences were observed. The surface appeared quite flat in all cases and no large pores (larger mesopores or macropores) could be detected in the SEM images. Krypton adsorption measurements confirm this by a specific surface area below $20 \mathrm{~cm}^{2} / \mathrm{cm}^{2}$. In spite of a strong influence on the deposition as seen in the current, no material with a developed porosity was obtained by adding small organic acids to the deposition mixture.

Surfactants as opposed to small organic acids are known to self-assemble into micellar aggregates, which can serve as templates in the synthesis of mesoporous molecular sieves. Also in electrodeposition, the solid/liquid interface of the substrate in the plating bath should provide a unique environment for surfactant assembly. Since negatively charged head groups are needed to bind to the growing $\mathrm{ZnO}$ film, we concentrated our studies on SDS as a prominent representative.

SDS was added to the deposition bath in different final concentrations ranging from $50 \mu \mathrm{M}$ to $1 \mathrm{mM}$ either in one step or by multiple addition. When SDS (b)

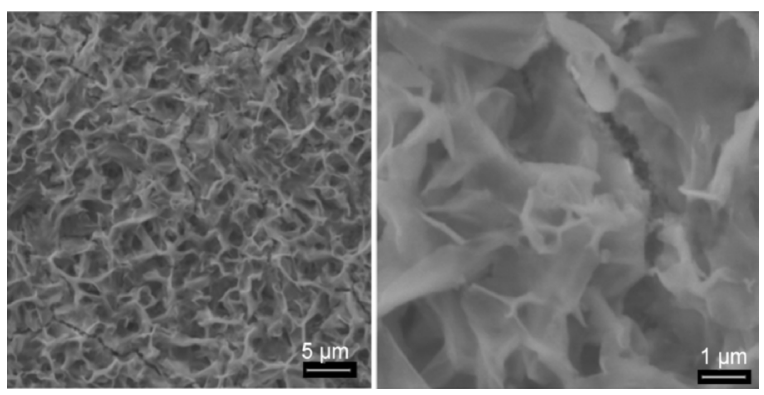

Fig. 4. Time evolution of the cathodic current density in the presence of $600 \mu \mathrm{M}$ SDS for three individual experiments lasting 5, 10, 20, $30 \mathrm{~min}$ (a) and SEM images of the deposited $\mathrm{ZnO}$ within $20 \mathrm{~min}$ in the presence of $600 \mu \mathrm{M}$ of SDS (b).

was added step-wise to the electrodeposition bath, only a small influence on the cathodic current density was detected. However, the course of electrodeposition changed quite strongly when the concentration of SDS exceeded $400 \mu \mathrm{M}$. While below this limit almost no influence was detected, for concentrations above $600 \mu \mathrm{M}$ (up to $1 \mathrm{mM}$ ) the films were mechanically instable and full of cracks. Stable films without cracks, but strongly altered morphology were obtained for $600 \mu \mathrm{M}$ SDS. The cathodic current of the electrodeposition in the presence of $600 \mu \mathrm{M}$ of SDS increased within approximately $200 \mathrm{~s}$ to a constant final value of $2.2 \mathrm{~mA} / \mathrm{cm}^{2}$, nicely reproduced also for subsequent individual experiments (Fig. 4a). The observed steep increase in current up to a maximum value is typical for three-dimensional crystallization. The $\mathrm{ZnO}$ films deposited in the presence of $600 \mu \mathrm{M}$ SDS were highly crystalline as proven by XRD, up to $9 \mu \mathrm{m}$ thick at a linear increase in average thickness with the deposition time and highly porous (Fig. 4b) with a specific surface area of up to $650 \mathrm{~cm}^{2} / \mathrm{cm}^{2}$ as obtained by Krypton adsorption [19].

FT-IR spectra measured by attenuated total reflection (ATR) as well as EDX analysis confirmed the incorporation of SDS in the lamellae of $\mathrm{ZnO}$ seen in SEM (Fig. 4b). In order to allow the preparation of sensitized photoelectrodes in a subsequent step, SDS was desorbed either by treatment with diluted aqueous $\mathrm{KOH}$ leading to subtle differences in the morphology or, more efficiently, by extraction with ethanol without disturbing the crystallinity of $\mathrm{ZnO}$. Photosensitizers like Eosin Y, TSPcZn or TSTPPZn could be incorporated from dye solutions. The dye uptake was lin- 


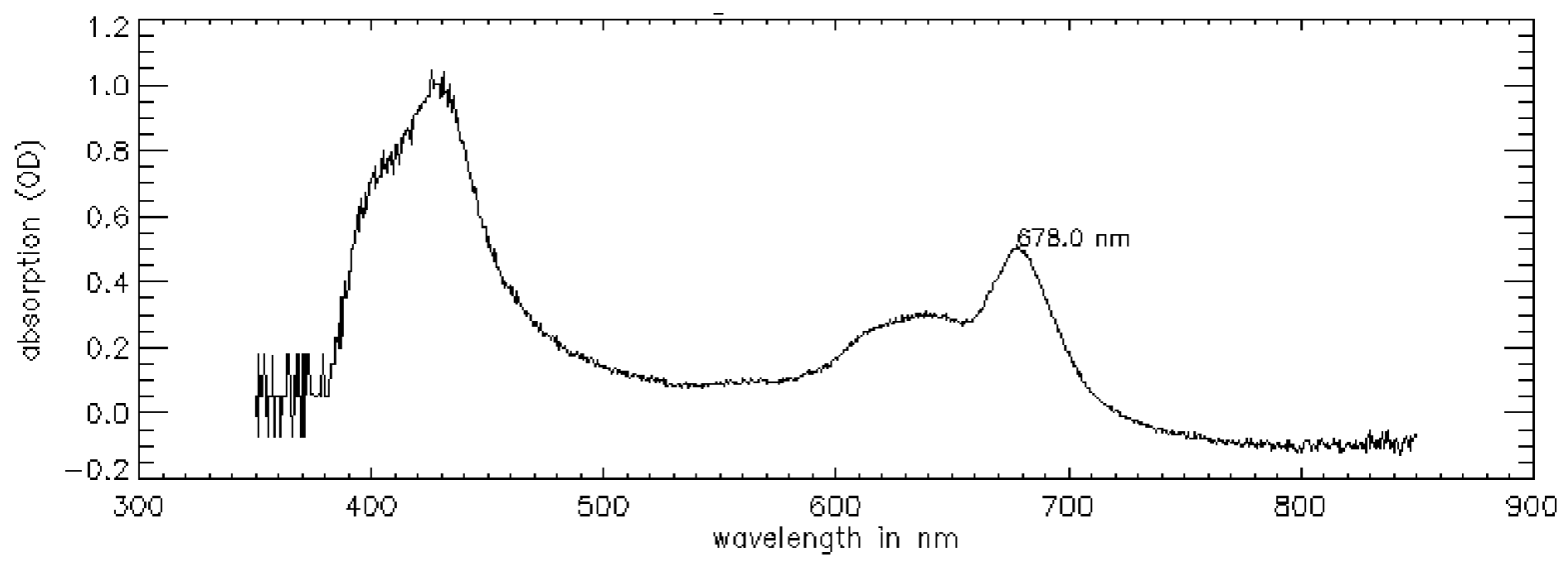

Fig. 5. Optical absorption spectrum of a porous $\mathrm{ZnO}$ film prepared in the presence of SDS as SDA with TSTPPZn and TSPcZn both adsorbed following removal of SDS.

early correlated with the average film thickness of $\mathrm{ZnO}$ deposited in the presence of SDS proving the uniform structure of the films. Photoelectrochemical experiments showed that the IPCE values were again considerably higher than those of the one-step films of Eosin $\mathrm{Y} / \mathrm{ZnO}$. The high values of $\mathrm{ZnO}$ grown in the presence of Eosin Y, however, could not be reached, which was most likely caused by an increased level of electron traps in the present SDS-grown $\mathrm{ZnO}$ as indicated in a rather slow increase of the photocurrent within $0.1-$ $30 \mathrm{~s}$ at the beginning of illumination [22]. Figure 5 shows the optical absorption of SDS-grown $\mathrm{ZnO}$ with TSTPPZn (absorption at $\sim 420 \mathrm{~nm}$ ) and TSPcZn (absorption at $\sim 680 \mathrm{~nm}$ ) leading to good panchromatic absorption. The IPCE values of TSTPPZn/ZnO films following the two-step preparation method were about 50 times higher than the values for films obtained in one step with TSTPPZn present already during deposition of $\mathrm{ZnO}$ [22].

\subsection{Model Reactions at ZnO Surfaces under UHV Conditions}

The model experiments served to explain the variation in the crystal morphology of the electrochemically deposited $\mathrm{ZnO}$ films depending on the preparation conditions and the chosen SDA in the deposition bath. The self-assembly of $\mathrm{ZnO}$ in the presence of different SDA molecules was attributed to a different strength of their interaction with different crystal planes and a resulting preferential growth of $\mathrm{ZnO}$ into specific crystallographic directions [13]. Single-crystals of $\mathrm{ZnO}$ with different orientations were used as model sur- faces. The O-terminated $\mathrm{H}(1 \times 1)-\mathrm{ZnO}(000-1)$ and the mixed-terminated $\mathrm{ZnO}(10-10)$ surfaces were used as a substrate to deposit thin films of phthalocyanines and structurally related dye molecules. In order to provide compatibility to the UHV conditions mandatory for this work, the molecules had to be deposited by physical vapour deposition and the chemical anchor groups had to be avoided. Instead, the unsubstituted parent compounds were studied in situ to serve as models for the hybrid systems. When the unsubstituted phthalocyaninatozinc (PcZn) was deposited on either $\mathrm{ZnO}(000-1)$ or $\mathrm{ZnO}(10-10)$ clearly different optical absorption spectra with significantly different splitting patterns in the electronic transitions were obtained, indicating a significantly different intermolecular coupling and hence significantly different growth of these molecules on the different crystal faces of $\mathrm{ZnO}$ (Fig. 6). Beyond the clear influence of acid groups on $\mathrm{ZnO}$ growth as apparent from the electrochemical study (Fig. 3), also the molecular centre of the dye molecules had an interaction different to the two $\mathrm{ZnO}$ faces leading to the different molecular aggregation. This observation is of relevance beyond the influence of dyes as SDA on film growth but indicates different electronic coupling of the centre of the chromophores to the different $\mathrm{ZnO}$ planes. Such electronic coupling, however, will play a decisive role in the process of sensitization and needs to be pursued further. Since the substrate was oriented almost perpendicular to the analyzing light beam (parallel to its field vector) the higher integral absorbance (proportional to $* \mathrm{R} / \mathrm{R}$ ) for comparable average film thickness indicates that the molecular transition dipole of PcZn is oriented close to par- 


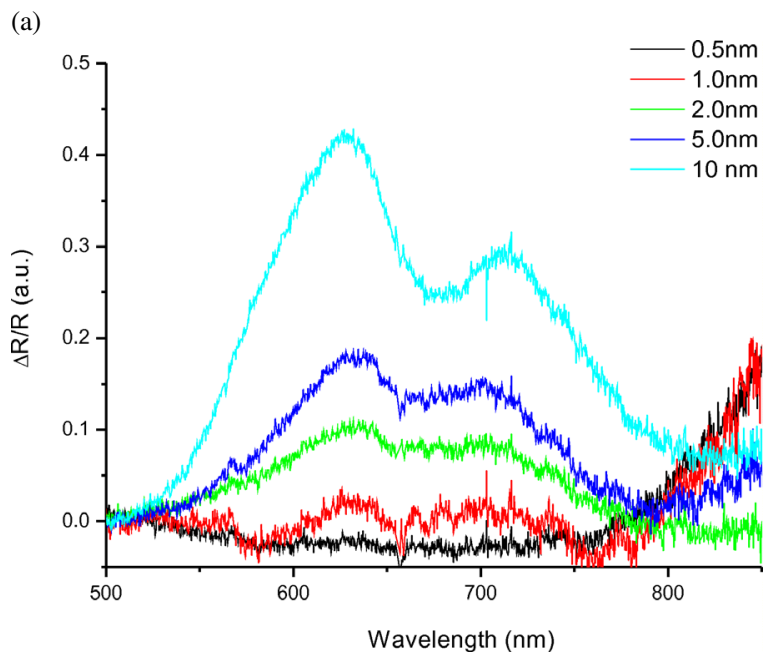

(b)

Fig. 6. Optical reflection spectrum of PcZn as a function of average film thickness (calibration via quartz micro balance) when deposited on (a) $\mathrm{ZnO}(000-1)$ or (b) $\mathrm{ZnO}(10-10)$.

allel to the substrate surface ("lying") when deposited on $\mathrm{ZnO}(10-10)$ whereas it is oriented close to perpendicular ("standing") when deposited on $\mathrm{ZnO}(000-1)$.

Since the hybrid materials of $\mathrm{ZnO}$ were prepared from aqueous precursor solutions, water adsorption on different $\mathrm{ZnO}$ crystal planes was studied. Furthermore layer growth of water on $\mathrm{ZnO}$ is also a good model to mimic the formation of hydrogen bonds which are also of importance for interaction of $\mathrm{ZnO}$ with dyes containing carboxylic, sulphonic, phosphoric, $\mathrm{OH}, \mathrm{NH}_{2}$ or related functional groups. While water adsorption on $\mathrm{ZnO}(10-10)$ was already reported

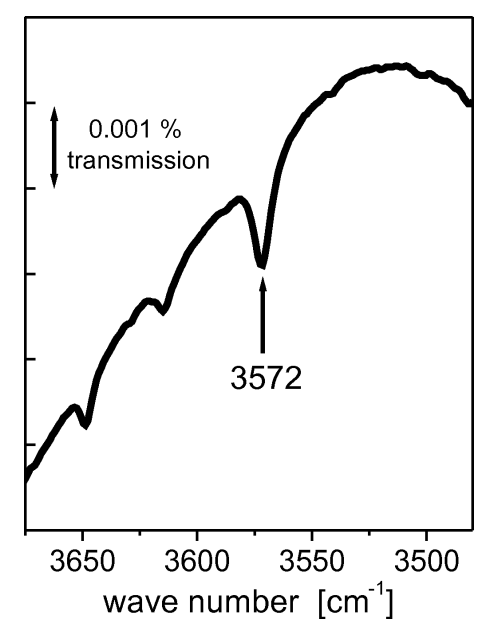

Fig. 7. Vibrational spectrum of the $\mathrm{OH}$-stretching region of the clean $\mathrm{H}(1 \times 1) \mathrm{O}-\mathrm{ZnO}(000-1)$ crystal recorded in reflection at grazing incidence $\left(6^{\circ}\right)$. in the literature [23], multilayer adsorption of water on the polar $\mathrm{ZnO}(000-1)$ had not been studied. Exposure of a clean $\mathrm{ZnO}(000-1)$ surface to water vapour at room temperature led to the formation of a sharp, welldefined hexagonal low energy diffraction (LEED) pattern revealing the presence of a $(1 \times 1)$ surface structure. Investigations with reflection high energy electron diffraction (RHEED) at various azimuthal angles have shown that no reconstruction is apparent parallel to the surface. Infrared spectroscopy was used to further analyze the interaction (Fig. 7). The IR spectrum of the $\mathrm{OH}$ stretching region of a $\mathrm{ZnO}(000-1)$ shows the vibrational band at $3572 \mathrm{~cm}^{-1}$ that is unique for the $\mathrm{ZnO}$ surface. The signals at $3648 \mathrm{~cm}^{-1}$ and $3615 \mathrm{~cm}^{-1}$ are due to absorptions from some of the optical components as shown by reference measurements without $\mathrm{ZnO}$ [24]. These experiments provide the first direct evidence that the $\mathrm{O}-\mathrm{ZnO}(000-1)$ is hydrogen terminated under the chosen experimental conditions. $\mathrm{OH}$-groups are known to play an essential part within the growth of $\mathrm{ZnO}$ from aqueous precursor solutions. Further adsorption of water led to multilayers on this well defined single crystal of hydroxylterminated $\mathrm{H}(1 \times 1)$-O- $\mathrm{ZnO}(000-1)$ surface as well ordered mono-, bi- and multilayers of $\mathrm{D}_{2} \mathrm{O}$ and $\mathrm{H}_{2} \mathrm{O}$. Temperature-programmed desorption yielded activation energies of $40.3 \mathrm{~kJ} / \mathrm{mol}$ and $44.2 \mathrm{~kJ} / \mathrm{mol}$. Further exposure to water at $113 \mathrm{~K}$ resulted in the formation of amorphous 3D-islands. These results differ substantially from results on the mixed termi- 
(a)

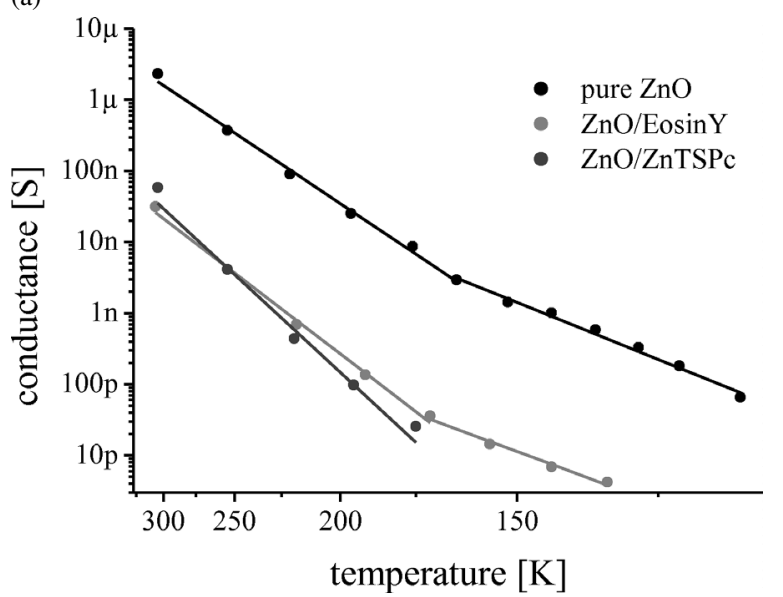

(b)

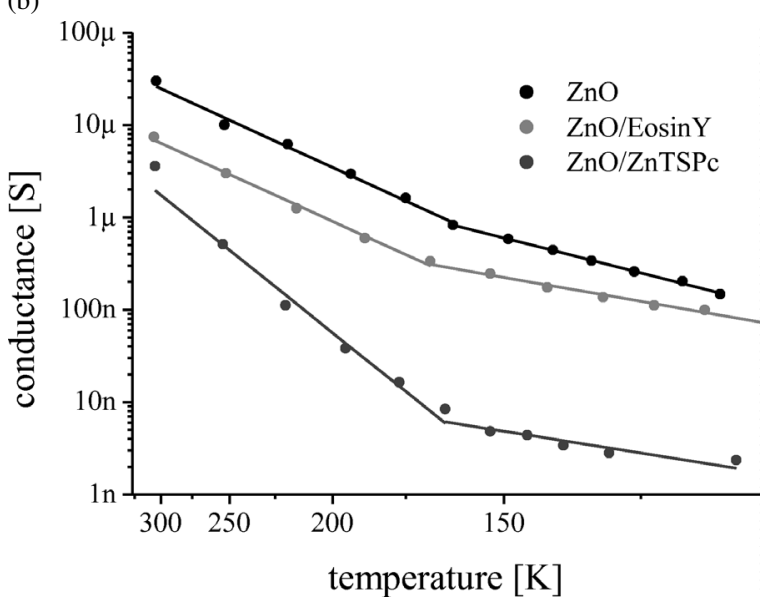

Fig. 8. Arrhenius plots of the temperature dependent conductance of either pure $\mathrm{ZnO}$ or $\mathrm{ZnO}$ with either Eosin Y or $\mathrm{ZnPTS}$ adsorbed in (a) darkness and (b) under illumination with white light of $0.1 \mathrm{~mW} / \mathrm{cm}^{2}$.

nated $\mathrm{ZnO}(10-10)$, where a more complex scenario for $\mathrm{ZnO}(10-10)$ has been found in which every second water molecule of a full monolayer dissociated while the remaining water molecules were strongly bound by a "key-lock" type structural arrangement [23]. The resulting water adlayer formed a well-defined $(2 \times 1)$ superlattice of intact water molecules which is stable up to $360 \mathrm{~K}$. The comparison of these results indicates that the $\mathrm{ZnO}(10-10)$ surface should exhibit a more pronounced ability to participate in hydrogen bridging with adsorbed SDA or sensitizers and that the two studied surfaces show significantly different interaction with $\mathrm{OH}$ and hence different optimum adsorption geometries and preferred binding sites for the studied SDA and sensitizers leading to the different film morphologies observed in electrodeposition.

\subsection{Electrical Conduction and Photoconduction in ZnO/Dye Hybrid Materials}

Since samples of $\mathrm{ZnO}$ grown in the presence of Eosin Y or other small SDA molecules often showed short circuits upon evaporation of metal contacts, the electrical characterization is focussed on $\mathrm{ZnO}$ grown in the presence of SDS (Fig. 4), which could be contacted safely. Both pristine $\mathrm{ZnO}$ electrodes, from which SDS had been removed by $\mathrm{KOH}$ treatment, and $\mathrm{ZnO}$ electrodes, to which either EosinY or TSPcZn was subsequently adsorbed, were studied. A quadratic dependence of the current on applied voltage was observed for all three materials, speaking for spacecharge-limited currents (SCLC) [25] caused by attenu- ation of the applied electric field by the injected charge carriers. This model seems adequate for the electrodes in these conduction measurements since no chargecompensating ions are available in the pores. This situation is of course different from the photoelectrochemical experiments where ions are present and a combined conduction of electrons in $\mathrm{ZnO}$ and ions in the pores filled by electrolyte leads to clearly enhanced currents. The conduction measurements therefore yield insight into the electrical properties of the pure electrode material without electrolyte.

Electrical conduction and photoconduction upon illumination at characteristic wavelengths were studied at low applied potential avoiding the complications of space charge limitation. The experiments were also performed under variation of the sample temperature (Fig. 8). With decreasing temperature, the conductivity of both the dark and the illuminated samples decreased by orders of magnitude according to

$$
\sigma=\sigma_{0} \exp \left(-\frac{\Delta E}{2 k T}\right),
$$

where $\Delta E$ gives the activation energy of conduction. It consists of a contribution also from a temperature dependence of the charge carrier mobility but dominated by a thermal activation of the charge carrier concentration and is described in the most straightforward way by the energy difference between an electron trap state and the conduction band in the case of $\mathrm{n}-\mathrm{ZnO}$ [26]. $k$ is Boltzmann's constant, and $T$ is the sample temperature. The fits of this function to the ex- 
perimental data show good agreement with two characteristic activation energies $\Delta E_{1}$ and $\Delta E_{2}$ and a transition temperature in the range of $170 \mathrm{~K}$ for all samples. The calculated values are $\Delta E_{1}=238 \mathrm{meV}$ and $\Delta E_{2}=$ $396 \mathrm{meV}$ for the pure $\mathrm{ZnO}, \Delta E_{1}=220 \mathrm{meV}$ and $\Delta E_{2}=$ $452 \mathrm{meV}$ for $\mathrm{ZnO} /$ Eosin $\mathrm{Y}$, and $\Delta E_{2}=548 \mathrm{meV}$ for the $\mathrm{ZnO} / \mathrm{TSP} \mathrm{Zn}$. We relate the two different activation energies to trap bands at these energies below the conduction band of $\mathrm{ZnO}$. At the transition temperature $T_{0} \approx 170 \mathrm{~K}$, the same concentration of electrons is excited from each trap band and

$$
n_{1} \exp \left(-\frac{E_{1}}{k T_{0}}\right)=\exp \left(-\frac{E_{2}}{k T_{0}}\right)
$$

then leads to a relation of trapped charge in the two trap bands of $n_{2} / n_{1} \approx 5 \cdot 10^{4}$ for the pure $\mathrm{ZnO}$. The adsorption of the sensitizers had a clear influence on the distribution of the traps in the material as already seen in the decrease of conductivity and confirmed by the observed changes in the activation energy. Introduction of the sensitizers led to a trap distribution extending further into the band gap leading to the increased activation energies and lower conductivity.

Under illumination the conductivity rose by some orders of magnitude and the activation energies decreased for all three types of materials. For the pure $\mathrm{ZnO}$ deposited in the presence of SDS this can be explained by a high trap concentration leading to a situation similar to amorphous semiconductors [27, 28], thereby confirming the high trap concentration already concluded from the photoelectrochemical measurements. For the dye loaded $\mathrm{ZnO}$ illumination leads to an excitation of electrons from the ground state of the dyes. From this first excited state electrons can be transferred to the conduction band of $\mathrm{ZnO}$ as also seen in the photoelectrochemical experiments. Therefore, the concentration of electrons in the conduction band of the $\mathrm{ZnO}$ /dye hybrid material increased, and, hence, the conductivity rose. The highest increase of the conductivity under illumination could be observed in case of the Eosin Y sensitized material, explained by a higher amount of Eosin $\mathrm{Y}$ in the hybrid material when compared with TSPCZn. We calculate the thermal activation energy under illumination to $\Delta E_{1}=$ $112 \mathrm{meV}$ and $\Delta E_{2}=202 \mathrm{meV}$ for the pure $\mathrm{ZnO}, \Delta E_{1}=$ $84 \mathrm{meV}$ and $\Delta E_{2}=200 \mathrm{meV}$ for the Eosin Y loaded material, and $\Delta E_{1}=70 \mathrm{meV}$ and $\Delta E_{2}=354 \mathrm{meV}$ for the ZnTSPc loaded $\mathrm{ZnO}$. The decrease in activation energy relative to the dark conductivity by about a factor
0.5 can again be regarded typical for amorphous materials, if aside from electron traps near the conduction band also hole traps near the valence band are considered $[27,28]$.

The observed photoconduction showed rather slow increase and even slower decrease when the light was switched on and off, pointing to a large concentration of deep traps. Persistent photoconductivity (PPC) was observed also earlier for $\mathrm{ZnO}[29,30]$ or other II-VI semiconductors [31]. Typical relaxation times for the decreasing photoconductivity were in the range of some hours up to several days, but the increasing conductivity under illumination was found to stem from faster process (Fig. 9). Different models have been proposed to explain the origin of PPC and in many cases, PPC was attributed to metastable defects present between a shallow and a deep trap state $[29,30]$. The dependence of the observed slow changes was studied in dependence on the illumination wavelength to differentiate between contributions of the $\mathrm{ZnO}$ matrix and adsorbed dye molecules. A photoconductivity signal also for pure $\mathrm{ZnO}$ already occurs under illumination with red light corresponding to a photon energy of $1.9 \mathrm{eV}$, far below the band gap energy and increased for higher photon energies, again typical for materials with a high concentration of traps. $\mathrm{ZnO}$ with adsorbed Eosin Y showed a particularly high photocurrent under illumination with green light, corresponding to the absorption peak of Eosin Y around $520 \mathrm{~nm}$. The buildup and decay transients of the photocurrent follow a non-exponential time dependence and functions of the form

$$
I=I_{0}\left(1-\exp (-t / \tau)^{\gamma_{\mathrm{r}}}\right)
$$

which could be fitted to the rise of the conductivity under illumination and of the form

$$
I=I_{0} \exp (-t / \tau)^{\gamma_{\mathrm{d}}}
$$

to the decay when the illumination was switched off. The corresponding fits are shown by solid lines in the plots of Figure 9. The curves could be jointly fitted with $\gamma_{\mathrm{r}}=0.76$ for all rising curves and $\gamma_{\mathrm{d}}=0.57$ for the decay curves, indicating one respective trapping mechanism in the electrodes. The characteristic time constant $\tau$ describes the initial relaxation process, when the light is switched on or off. It spreads over a range between $5300 \mathrm{~s}$ and $23500 \mathrm{~s}$, confirming widely different concentration and energy distribution of trap levels in the different samples. The smallest value was 
(a)

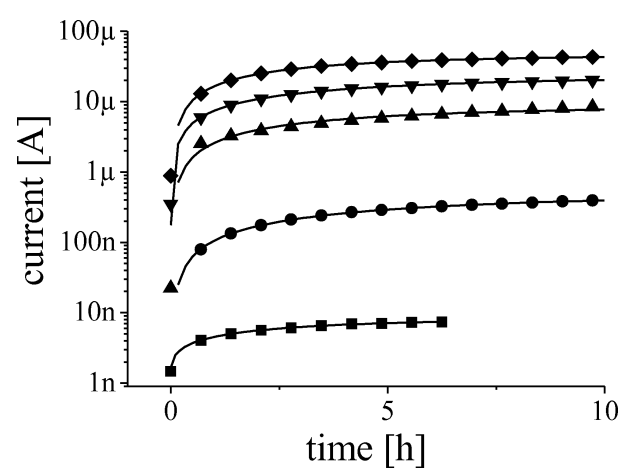

(c)

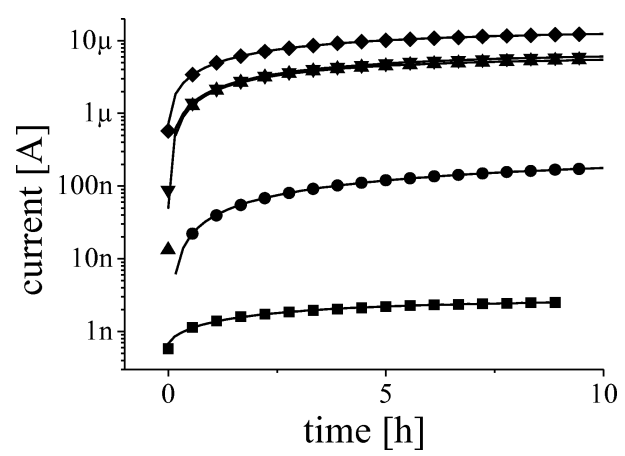

(b)

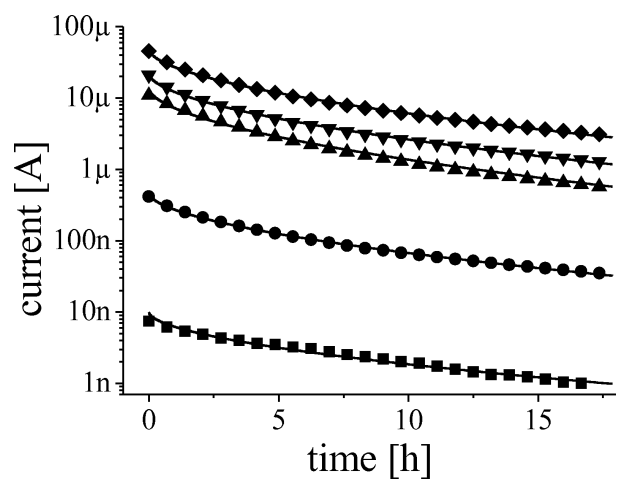

(d)

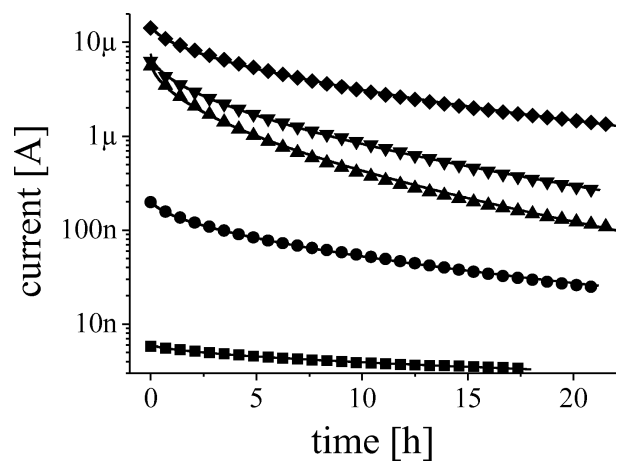

Fig. 9. Photocurrent versus time curves for (a) $\mathrm{ZnO}$ and (c) $\mathrm{ZnO} /$ Eosin $\mathrm{Y}$ after illumination with five different excitation wavelengths (LEDs $656 \mathrm{~nm}, \bullet 594 \mathrm{~nm}, \boldsymbol{\Delta} 534 \mathrm{~nm}, \boldsymbol{\nabla} 474 \mathrm{~nm}, \bullet 440 \mathrm{~nm}$ ) was switched on, for (b) $\mathrm{ZnO}$ and (d) ZnO/Eosin Y samples after illumination was switched off. The thin solid lines indicate stretched exponential fits.

reached for $\mathrm{ZnO}$ with adsorbed Eosin $\mathrm{Y}$, when the illumination with green light was switched off, explained by fastest saturation of the effect for strongly absorbed light.

The observed changes on the time scale of hours could only be observed because the samples were analyzed in a pure state in an inert vacuum environment. In the photoelectrochemical experiments in the presence of a redox electrolyte, relaxations occurred within 0.1-30 s because of competing charge transfer [22]. Nevertheless both types of experiments clearly showed the strong influence of trap levels on the photoconduction and photovoltaic characteristics of the present $\mathrm{ZnO}$ electrodes prepared in the presence of SDS.

\section{Conclusions}

The interplay of experimental methods from a range of different fields has been used to determine the key parameters to optimize the performance of sensitized $\mathrm{ZnO}$ electrodes prepared by electrodeposition. Water adsorption was found to play a crucial role on bare surfaces of $\mathrm{ZnO}$ and adsorption of different structure directing agents (SDA) was also found to directly influence the observed current during electrochemical deposition and the resulting morphology of the $\mathrm{ZnO}$ thin films. The current of the $\mathrm{O}_{2}$-reduction and hence $\mathrm{ZnO}$ precipitation was found to increase not only upon addition of Eosin $\mathrm{Y}$ as an electrocatalyst but also in the case of organic acids like toluenesulfonic acid or benzenetetracarboxylic acid lifting the blocking of the surface by $\mathrm{Zn}^{2+}$-addition [20]. Crystalline $\mathrm{ZnO}$ with a large accessible inner surface as determined by gas sorption measurements was in particular obtained by addition of the anionic surfactant SDS. Deposition of unsubstituted phthalocyanines as model chromophores showed different adsorption and aggregate formation on the different pure $\mathrm{ZnO}$ surfaces in UHV indicating different electronic interaction of the chromophore system with different faces of $\mathrm{ZnO}$. It can therefore be assumed that aside from acidic chemical anchor groups also the interaction with the chromophore sys- 
tem plays a role in $\mathrm{ZnO}$ crystallization. Consequences of the electronic coupling of the chromophores on the photoelectrochemical performance of electrodes have to be assumed and should be investigated further. Temperature-dependent measurements of the electrical conduction and photoconduction under illumination at different wavelengths showed the presence of deep trap levels in the porous $\mathrm{ZnO}$ matrix and also in the hybrid materials with adsorbed sensitizers leading to long response times and persistent photoconduction in the samples if measured in vacuum. Photoelectrochemical measurements in the presence of a redox electrolyte showed much faster response times because of fast interactions with these trap levels. A detailed characterization of the electrode kinetics clearly revealed the relevance of an optimized inner surface area with adsorbed sensitizers that are accessible by the redox electrolyte and of a maintained high electrical conductivity at preferably low trap density also in the porous $\mathrm{ZnO}$ matrix. These parameters reflect the need for a good accessibility of the sensitizers for both electronic transport in the semiconductor matrix and ionic transport in the electrolyte. Both transport pathways are attenuated by an increased surface area of the electrodes. An increased surface area, however, allows an increased sensitizer concentration and hence increased light harvesting. Experiments are on the way to further optimize the materials by a strategic pore design of different pore sizes and their optimum distribution in the film.

\section{Experimental}

The synthesis and preparation of 5,10,15,20-tetrakis (4-sulfonatophenyl)porphyrinatozinc (TSTPPZn) and 2,9,16,23-tetrasulfophthalocyaninatozinc(II) (TSPcZn) was performed as reported earlier [32], all other chemicals were purchased commercially. The electrodeposition of $\mathrm{ZnO} /$ dye hybrid materials was carried out in a three electrode single compartment cell containing $70 \mathrm{~mL}$ of solution with a saturated calomel electrode (SCE) as reference electrode, a $\mathrm{Zn}$ wire as counter electrode and $2.5 \times 1.5 \mathrm{~cm}^{2}$ pieces of F-doped $\mathrm{SnO}_{2}$ on glass (ASAHI GLASS) as working electrode under potentiostatic control (Wenking Potentiostat ST 88) at $-0.9 \mathrm{~V}$ vs. SCE for 30 minutes at $70{ }^{\circ} \mathrm{C}$. The one-step electrodepositions were carried out from aqueous solutions with $0.1 \mathrm{M} \mathrm{Zn}\left(\mathrm{NO}_{3}\right)_{2}$ and $25-50 \mu \mathrm{M}$ of the dyes. The "two-step" films were prepared from $\mathrm{ZnO} / \mathrm{Eosin} \mathrm{Y}$ (or $\mathrm{ZnO} / \mathrm{SDS}$, respectively) grown as described above, but from an oxygen-saturated solution of $5 \mathrm{mM} \mathrm{ZnCl}_{2}$
(FLUKA, > 98\%), $0.1 \mathrm{M} \mathrm{KCl}(\mathrm{ROTH},>99 \%)$ and $50 \mu \mathrm{M}$ Eosin Y (ALDRICH) or $600 \mu \mathrm{M}$ SDS and on a rotating electrode (500 RPM) [19]. The SDA was then desorbed overnight by a treatment in aqueous $\mathrm{KOH}$ (pH 10.5). Different sensitizers were subsequently adsorbed from solutions in ethanol or water. UV-vis spectra were measured in transmission using a HITACHI U-3000 spectrometer or a PERKIN ELMER Lambda 9 using air as reference. The film thickness was measured by an ALPHASTEP or VEECO Dektak 3 surface profiler. The dye content of the films was analyzed by UV-vis absorption spectroscopy following dissolution of the films in $7 \mathrm{~N}$ aqueous $\mathrm{NH}_{3}$ solutions. The surface area of the films was determined from adsorption isotherms of Krypton at $77 \mathrm{~K}$ measured by an ASAP 2010 apparatus (Micromeritics). Prior to each adsorption measurement, samples were outgassed at $150{ }^{\circ} \mathrm{C}$ over night, this temperature being the upper limit of the stability of the organic components contained within the films. For the determination of the small surface areas of thin films containing only about $1 \mathrm{mg}$ of $\mathrm{ZnO}$ per $\mathrm{cm}^{2}$, the adsorption of Krypton at $77 \mathrm{~K}$ was chosen because its saturation vapour pressure is low at this temperature. Consequently the "dead space" correction for gas molecules that are not adsorbed is small enough to measure the low amount of adsorbed gas with reasonable precision [17].

The photoelectrochemical study was performed in a conventional three-electrode arrangement in a $5 \mathrm{~mL}$ glass cell with the deposited thin film as a window of the cell illuminated from the glass/FTO side and used as the working electrode, a Pt counter electrode and a $\mathrm{Ag} / \mathrm{AgNO}_{3}$ reference electrode with acetonitrile (ROTH, 99.9\%) as internal solvent. A 1:4 by volume mixture of acetonitrile with ethylene carbonate (FLUKA, > 99\%) dissolving 0.5 M tetrabutyl-ammonium iodide (TBAI, SIGMA, 99\%) and $0.05 \mathrm{M}$ Iodine (SCHARLAU, 99.8\%) was used as electrolyte. The measurements were performed at a potential with negligible dark currents $\left(-0.2 \mathrm{~V}\right.$ vs $\left.\mathrm{Ag} / \mathrm{AgNO}_{3}\right)$. For the time-resolved measurements, an ORIEL $1000 \mathrm{~W}$ xenon arc lamp equipped with a water filter and a UV cutoff filter to restrict illumination to the visible range $(385 \mathrm{~nm}-900 \mathrm{~nm})$ at $200 \mathrm{~mW} \mathrm{~cm}{ }^{-2}$ was used. The illumination time of the electrode was controlled using a mechanical shutter. The shutter needed about $10 \mathrm{~ms}$ to reach a completely open (or closed) position as measured with a SIEMENS SFH 291 silicon-PIN-photodiode. The potentials and currents were measured with a JAISSLE Bi-Potentiostat-Galvanostat with a rise 
time of $100 \mu$ s connected to a HAMEG HM 305 oscilloscope. Photocurrent spectra were measured with a BUNKO KEIKI CEP-2000 spectral sensitivity analyzing system adjusted to $10^{16}$ photons $\mathrm{cm}^{-2} \mathrm{~s}^{-1}$. The results are generally reported in terms of the IPCE (Incident Photon Conversion Efficiency), the amount of electrons in the external circuit divided by the amount of photons incident on the electrode. To provide an estimate of the sensitisation efficiency of the dyes in the different electrodes, however, the observed photocurrent was also normalised on the dye content to obtain a number comparable to a turnover frequency in catalysis [33] by dividing the photocurrent density (in terms of electrons generated per second in a unit electrode area) by the dye content per unit electrode area.

The model adsorption and desorption experiments at single crystalline $\mathrm{ZnO}$ faces were performed in a ultrahigh vacuum system equipped with RHEED (reflection high energy electron diffraction), UV-vis spectroscopy, IR-spectroscopy and thermal desorption spectroscopy. For the IR experiments the $\mathrm{H}(1 \times 1)-\mathrm{ZnO}(000-1)$ surface was prepared by cooling the single crystal $\mathrm{ZnO}$ substrate to $130 \mathrm{~K}$ before applying repeated cycles of argon-ion bombardment at $473 \mathrm{~K}$ for $20 \mathrm{~min}$ and annealing to $873 \mathrm{~K}$ for $5 \mathrm{~min}$ (each cycle) before ultrapure water vapour was leaked into the chamber. A similar protocol was used also for $\mathrm{ZnO}$ pretreatment before deposition of the organic model compounds from Knudsen evaporation cells.

[1] H. Tributsch and M. Calvin, Photochem. Photobiol. 14, 95 (1971).

[2] H. Gerischer and F. Willig, Top. Curr. Chem. 61, 31 (1976).

[3] A. J. Nozik and R. Memming, J. Phys. Chem. 100, 13061 (1996).

[4] M. Grätzel, Prog. Photovolt: Res. Appl. 14, 429 (2006).

[5] M. Izaki and T. Omi, Appl. Phys. Lett. 68, 243 (1996).

[6] S. Peulon and D. Lincot, Adv. Mater. 8, 166 (1996).

[7] B. Mari, M. Mollar, A. Mechkour, B. Partiti, M. Perales, and J. Cembrero, Microelectronics Journal 35, 79 (2004).

[8] T. Oekermann, T. Yoshida, C. Boeckler, J. Caro, and H. Minoura, J. Phys. Chem B 109, 12560 (2005).

[9] D. Lincot, Thin Solid Films 487, 40 (2005).

[10] B. Illy, B. A. Shollock, J. L. MacManus-Driscoll, and M. P. Ryan, Nanotechnology 16, 320 (2005).

[11] A. Goux, T. Pauporte, and D. Lincot, J. Electroanal. Chem. 587, 193 (2006).

[12] Z. G. Chen, Y. W. Tang, L. S. Zhang, and L. J. Luo, Electrochim. Acta 51, 5870 (2006).
For the conduction measurements, $100 \mathrm{~nm}$ thick gold contacts with a diameter of $0.5 \mathrm{~mm}$ were evaporated on top of the electrodes and then a spring loaded gold pin was placed on top. Unwanted scrunching of the porous electrodes resulting in an unstable electrical contact and destruction of the films could be avoided by placing a thin slice of indium between the gold tip and the gold contact. The sample was mounted inside a chamber with dry nitrogen atmosphere and illuminated from the backside of the substrate. These conditions were necessary to avoid any interference by humidity or adsorbed gas molecules in the porous films. The characterization of the transverse photocurrent, i. e. the photocurrent flowing normal to the film plane, in the $\mathrm{ZnO} /$ dye samples was carried out by applying $200 \mathrm{mV}$ bias voltage via a Keithley 2400 source meter. In order to study the spectral response of the transversal film conductivity, we illuminated the samples by light emitting diodes (LEDs) of different emission spectra with a calibrated spectrally integrated light intensity of $0.25 \mathrm{~mW} / \mathrm{cm}^{2}$ at the position of the sample at an ambient temperature of $300 \mathrm{~K}$.

\section{Acknowledgement}

The authors are grateful to the Volkswagen Foundation for financial support (I/77722 (80314), I/77723, I/77724, I/77725) as well as to N. I. Jaeger (Univ. Bremen), T. Oekermann (Univ. Hannover), and D. Lincot (ENSCP Paris) for numerous fruitful discussions.

[13] T. Yoshida, M. Tochimoto, D. Schlettwein, G. Schneider, D. Wöhrle, T. Sugiura, and H. Minoura, Chem. Mater. 11, 2657 (1999).

[14] T. Yoshida, M. Iwaya, H. Ando, T. Oekermann, K. Nonomura, D. Schlettwein, D. Wöhrle, and H. Minoura, Chem. Commun. 400 (2004).

[15] K. Nonomura, T. Yoshida, D. Schlettwein, and H. Minoura, Electrochim. Acta 48, 3071 (2003).

[16] T. Loewenstein, K. Nonomura, T. Yoshida, E. Michaelis, D. Wöhrle, J. Rathousky, M. Wark, and D. Schlettwein, J. Electrochem. Soc. 153, A699 (2006).

[17] J. Rathousky, T. Loewenstein, K. Nonomura, T. Yoshida, M. Wark, and D. Schlettwein, Studies in Surface Science and Catalysis 156, 315 (2005).

[18] K. Nonomura, T. Loewenstein, E. Michaelis, D. Wöhrle, T. Yoshida, H. Minoura, and D. Schlettwein, Phys. Chem. Chem. Phys. 8, 3867 (2006).

[19] E. Michaelis, D. Wöhrle, J. Rathousky, and M. Wark, Thin Solid Films 497, 163 (2006).

[20] A. Goux, T. Pauporte, and D. Lincot, Electrochim. Acta 51, 3168 (2006). 
[21] T. Yoshida, T. Pauporte, D. Lincot, T. Oekermann, and H. Minoura, J. Electrochem. Soc. 150, C608 (2003).

[22] K. Nonomura, Dissertation, Universität Gießen, Gießen (Germany) 2006.

[23] B. Meyer, D. Marx, O. Dulub, U. Diebold, M. Kunat, D. Langenberg, and C. Wöll, Angew. Chem. Int. Ed. 43, 6642 (2004).

[24] M. Schiek, K. Al-Shamery, M. Kunat, F. Traeger, and Ch. Wöll, PCCP 8, 1505 (2006).

[25] A. Rose, Phys. Rev. 97, 1538 (1955).

[26] B. Sapoval and C. Hermann, Physics of Semiconductors, Springer, Berlin 1995.

[27] N. F. Mott and E. A. Davis, Physics of Amorphous Ma- terials, Longman Scientific and Technical, New York 1979.

[28] J. Z. Liu and S. Wagner, Phys. Rev. B 39, 11157 (1989).

[29] S. A. Studenikin, N. Golego, and M. Cocivera, J. Appl. Phys. 87, 2413 (2000).

[30] P. Sharma and K. Sreenivas, J. Appl. Phys. 93, 3963 (2003).

[31] H. X. Jiang and J. Y. Lin, Phys. Rev. Lett. 64, 2547 (1990).

[32] E. Michaelis, K. Nonomura, D. Schlettwein, T. Yoshida, H. Minoura, and D. Wöhrle, J. Porphyrins and Phthalocyanin 8, 1366 (2004).

[33] V. Parmon, A. V. Emeline, and N. Serpone, Intern. J. Photoenergy 4, 91 (2002). 